
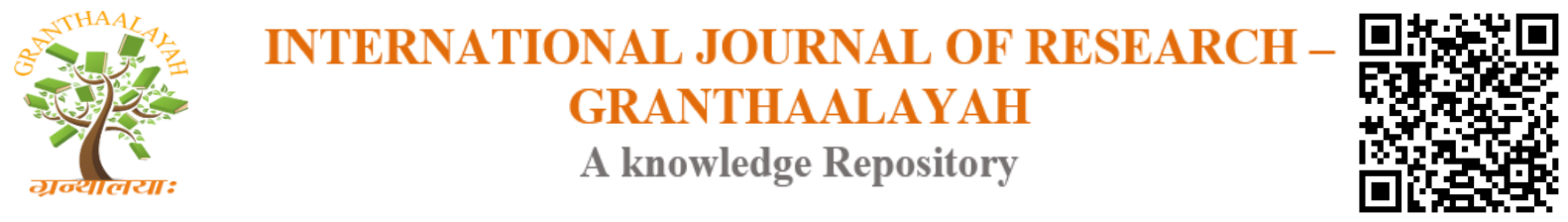

Management

\title{
CORRELATION OF THE PORTUGUESE STOCK MARKET WITH MAJOR GLOBAL CAPITAL MARKETS
}

\author{
Gualter Couto $^{* 1}$, Pedro Pimentel ${ }^{1}$, Ricardo Faria ${ }^{2}$ \\ ${ }^{*}$ School of Business and Economics, and CEEAplA; University of the Azores, Portugal \\ ${ }^{2}$ School of Business and Economics; University of the Azores, Portugal
}

This paper is financed by portuguese national funds throught FCP - Fundação para a Ciência e a Tecnologia, I.P., project number UID/ECO/00685/2016.

\begin{abstract}
In this paper, we will analyse the increase of correlations in the market during periods of crisis, given its importance to the management and optimization of the portfolio, and especially for risk diversification in portfolio management. An evaluation of the level of correlation between the stock markets is important for several reasons. First, it enables to evaluate changes in the patterns of correlation, and thus to make the proper adjustments in portfolios' investment. Second, policy makers are also interested in these correlations because of its implications for the stability of the financial system.

The correlation coefficients are biased measures of dependence when markets become more volatile. This paper explores the correlation of the Portuguese capital markets with the Asian, American, European and Latin American Spanish stock markets. To this end, we used the PSI-20 index, Nikkei 225, NASDAQ, S\&P 500, Euronext 100 and Ibex-35. Our analysis results show that the correlation does exist as a phenomenon during financial crises (Bear Market), reducing the benefits of portfolio diversification when most needed. Moreover, we believe that correlations have increased between the markets in recent years.
\end{abstract}

Keywords: Correlation; Volatility; Portfolio Diversification.

Cite This Article: Gualter Couto, Pedro Pimentel, and Ricardo Faria. (2017). "CORRELATION OF THE PORTUGUESE STOCK MARKET WITH MAJOR GLOBAL CAPITAL MARKETS." International Journal of Research - Granthaalayah, 5(7), 92-109. https://doi.org/10.29121/granthaalayah.v5.i7.2017.2110.

\section{Introduction}

This paper aims to obtain the level of correlation of the main Portuguese stock index that has some of the highest stock indexes. For this analysis, we select the index that will provide greater coverage of studies on the specificity of the actions of the stock market in Portugal. Potential investors willing to diversify their investments may use this study as an analysis of the volatility 
of their investment. To analyse the correlation between the Portuguese Capital Markets and the Asian, American, European and Spanish stock markets, we selected the main index for the evolution of the stock market in Portugal, the PSI-20, and compared the dynamics and major changes in the evolution of this index with some of the major stock indexes worldwide reference: Nikkei 225 (Japan), S \& P 500 (EUA), Euro Stoxx 50 (Eurozone), DJ Stoxx 600 (Europe), Russell 2000 (EUA) and Ibex-35 (Spain). Using the Pearson correlation coefficients we found that the correlation is higher with the Ibex 35, Eurostoxx 50 and DJ Stoxx 600; it is standard with S\&P 500 and Russell; and low with the Nikkei 225, but in recent years it has increased significantly. The correlation is higher in the Bear Market than in the Bull Market. Despite the creation of the PSI-20 on December $31^{\text {st }}$ we will focus our analysis over the last 10 years, i.e., from January $1^{\text {st }} 1999$ to December $31^{\text {st }} 2008$. In this period of time it is intended to analyse some of the most significant moments in the capital markets, particularly, the end of the Asian crisis (1998), the technology bubble (2000), September 11 (2001), the impact of Enron and telecommunications group Wordcom (2002) and, finally, the recent effect of Subprime (2008). For the sample period, we found that the correlation between returns in equity markets is strongly explained by market volatility. Furthermore, in terms of economic importance, note that large increases in volatility can change the correlations substantially. We found that the volatility of the Portuguese market is lower than the other indexes, and in the first years of our sample it is in counter cycle. The results show that the volatility in the markets is the main driver of correlation between the stock markets. The methodology for this work follows the work Flavin, Hurley and Rousseau (2000) and Serra (2002), Knif, Pynnonen and Kolari (2005) and Short (2007).

\section{Literature Review}

To answer why so many markets experienced an adverse crash, King and Wadhwani (1990) developed the idea of spreading market in which heavy falls, such as the United States, overflow into other markets. In their model, contagion occurs due to non-synchronous time in which market participants try to extrapolate the information from changes in market prices before the opening. This 'news' can be contaminated by the market, for specific information that should influence the market, being incorrectly incorporated into domestic prices. The contagion was found to increase the volatility of the markets. They also provide empirical evidence that stock prices of the London Stock Exchange tend to increase when the New York market opens, establishing a pattern of leader follower. King et al. (1994) show that little movement of cooperation in the stock market can be explained by observable economic factors, but this fact is mostly due to unobservable factors such as investor sentiment. Gillam et al. (2002) present a study in the FTSE (UK) where results show the strong correlation with the "good words" and "bad words" with the development of the index, showing that the correlation can be explained not only by volatility but also by market sentiment. Stulz and Karolyi (1996) analysed the movements of stock market returns in Japan and United States, and didn't found statistical significance between asset returns and macroeconomic announcements, to the exchange rate stocks, the returns titles Treasure or the effects of the industry. Ammer and Mei (1996) consider that the risk premium of the shares, rather than fundamental variables account for most of the movements across national indices. Longin and Solnik (1995) found that correlations are unstable over time. In addition, they provide empirical evidence that conditional correlations can be influenced by income from dividends and interest rates of short-term. In a similar exercise, 
Ramchand and Susmel (1998) showed that the correlations are time-dependent, since the correlation tends to increase when markets become more volatile. Bodart and Reding (1999) presented the main empirical result to reduce the variability of the exchange rate that leads to an increase in international correlation of returns on securities and stock market. Groenen and Franses (2000) used a technique of graphical representation (graphs of heat) to investigate the correlations in the stock market and its evolution over time. They did not found a wallet on the world market, but three groups of markets that break along geographic lines, ie, Europe, Asia and the United States. Heaney et al. (2000) report similar results. Among other studies that addressed the question of the relationship between markets with world crises, let's consider King and Wadhwani (1990) that investigated the impact of declining market in the United States in October of 1987 with the United Kingdom and Japan, and Kim and Lee (1993) have studied the same in 12 major stock markets. Calvo and Reinhart (1996) analyzed the impact of the Mexican peso crisis in 1994, about contagion in major financial markets. The general conclusion of these is that the correlation of the markets during the crisis increases significantly, indicating the existence of contagion effects in all markets. Hamao et al. (1990) and Edwards (1998) got the same conclusion by looking at the impact of volatility. Furthermore, Longin and Solnik (1995), Solnik et al. (1996), Ramchand and Susmel (1998) and Butler and Joaquin (2002) showed that the correlation between markets increases during periods of high volatility in which the reduction of benefits to portfolio diversification is most evident at times when they are most needed, considering the increase of correlation of the asset's categories around the world. An important study, Forbes and Rigobon (2002) investigated the question of equity markets being dependent of this contagion, defined as an increase in movement between the markets after a crash in one country and where the distance factor no longer remains. The study by Ang and Chen (2002) documented that the correlations are asymmetric for the rise and fall in markets, suggesting that volatility is not the factor driving up the market in times of crisis. In line with the analysis of correlations, both the upward and downward movements show that the correlations are, however, biased measures of dependence if taken in large general market movements. Consequently, since the real-world data cannot be characterized by homogeneity, the correlation coefficients are not necessarily so biased that require the use of Forbes and Rigobon (2002), suggesting that the contagion can often be present as a true phenomenon during the great financial crises. This result has important implications for defining the allocation and management of risks, since Solnik et al. (1996), Ramchand and Susmel (1998) and Butler and Joaquin (2002) showed how the change in the market affects the performance of an internationally diversified portfolio, without dynamic rebalancing. Ramchand and Susmel (1998) also showed that the correlations between the United States with other world markets are 2 to 3.5 times higher considering its state of high volatility, when compared to a situation of low volatility. These results suggest that volatility is a major driver of the correlation. However, applying the analysis of extreme value, Longin and Solnik (1995) argued that the correlation is not related to the volatility of the market itself, but with this trend. In these studies is shown that in international markets, especially in the case of negative returns, the correlations tend to increase, i.e., the correlation tends to increase in the Bear Market, but not in the Bull Market. It's observed that the correlation is mainly affected by market trends, rather than the volatility in periods of extreme returns. In this paper we present results showing that the correlations have increased between the markets from 1999 to 2008, which means that the increasing correlation found by Longin and Solnik (1995) for the period 1960 to 1990 has continued in recent years. This trend is probably ascribed to the increasing integration of financial markets in national stock markets around the world. 


\section{Methodology}

We began our research of the correlation of stock markets by adopting the Pearson correlation coefficient or simply type "Pearson's r", Pindyck and Rotemberg (1990). The $r$ is a concept well known to measure the linear relationship between two variables, is widely used in statistics to measure the level of the relationship between the linear related variables. For the Pearson $r$ correlation, both variables should be normally distributed, that is the case in the stock market, when we want to measure how two commodities are related to each other, this being the main reasons why we used this type of correlation, Khan e Ahmed (2009).

It, also, plays an important role in a number of conventional approaches in finance, such as the Capital Asset Pricing Model (CAPM) that has a correlation as a measure for the dependence of financial assets.

The Pearson coefficient of correlation is calculated using the following:

$$
r=\frac{\sum_{i=1}^{n}\left(x_{i}-\bar{x}\right)\left(y_{i}-\bar{y}\right)}{\sqrt{\sum_{i=1}^{n}\left(x_{i}-\bar{x}\right)^{2}} \cdot \sqrt{\sum_{i=1}^{n}\left(y_{i}-\bar{y}\right)^{2}}}
$$

In which $x_{1}, x_{2}, \ldots ., x_{n}$ e $y_{1}, y_{2}, \ldots ., y_{n}$ are the measured values of $\mathrm{X}$ and $\mathrm{Y}$, and $\bar{x}=\frac{1}{n} \sum_{i=1}^{n} x$ and $\bar{y}=\frac{1}{n} \sum_{i=1}^{n} y$ are the averages of both variables, i.e.:

$$
r=\frac{\sum_{i=1}^{n} x_{i} y_{i}-\frac{1}{n} \sum_{i=1}^{n} x_{i} \sum_{i=1}^{n} y_{i}}{\sqrt{\sum_{i=1}^{n} x_{i}^{2}-\frac{1}{n}\left(\sum_{i=1}^{n} x_{i}\right)^{2}} \cdot \sqrt{\sum_{i=1}^{n} y_{i}^{2}-\frac{1}{n}\left(\sum_{i=1}^{n} y_{i}\right)^{2}}}
$$

The correlation is defined only if both standard deviations are finite and nonzero. For the corollary of the inequality of Cauchy-Schwarz, the correlation cannot exceed 1 in absolute value. When the value of $r>0$ we use the term positive correlation, and in this case, as $X$ increases $Y$ also increases. When the value of $r<0$ we use the term negative correlation, and in this case as $\mathrm{x}$ increases, $\mathrm{Y}$ decreases. The higher the value of $\mathrm{r}$ (positive or negative), the stronger the association between $\mathrm{X}$ and $\mathrm{Y}$. The correlation takes an intermediate value in all other cases, indicating the level of linear dependence between the variables. If the variables are independent then $r=0$, means that there is no linear relationship. In the following (table 1 Williams (1968)), we provide a guide on how to interpret a correlation in words, given the numerical value. 
Table 1: Interpretation of correlation coefficient of Pearson

\begin{tabular}{ll}
\hline Absolute Value & Interpretation of $\boldsymbol{r}$ \\
\hline 0.00 a 0.19 & very weak correlation \\
\hline 0.20 a 0.39 & weak correlation \\
\hline 0.40 a 0.69 & moderate correlation \\
\hline 0.70 a 0.89 & strong correlation \\
\hline 0.90 a 1.00 & very strong correlation \\
\hline
\end{tabular}

The correlation between markets is important to calculate, because the investor can diversify his investment and dilute the possibility of correlation.

\section{Data}

This study aims to assess the correlation between the main index for the stock market in Portugal, the PSI-20 with some of the major stock indexes worldwide reference: Nikkei $225, \mathrm{~S} \&$ P 500, Euro Stoxx 50, DJ Stoxx 600, Russell 2000, Ibex-35.

Table 2: List of contents

\begin{tabular}{lll}
\hline Abbreviation & Index Name & Zone/ Country \\
\hline$\wedge$ N225 & NIKKEI 225 & Japan \\
\hline${ }^{\wedge}$ IBEX & IBEX 35 & Spain \\
\hline${ }^{\wedge}$ STOXX & DJ STOXX 600 & Europe \\
\hline$\wedge$ RUT & RUSSELL 2000 & USA \\
\hline${ }^{\wedge}$ STOXX50E & EURO STOXX 50 & Europe \\
\hdashline${ }^{\wedge}$ GSPC & S\&P 500 & USA \\
\hline$\wedge$ PSI20 & PSI 20 & Portugal \\
\hline
\end{tabular}

The PSI 20 (Portuguese Stock Index) is the benchmark stock market in Portugal, reflecting the evolution of prices of 20 stock issues with larger liquidity, selected in a universe of companies listed on Euronext Lisbon. The PSI 20 index was created on December 31, 1992. The market capitalization of emissions is set up by the Free Float (number of shares free), where each issue cannot be weighed more than $20 \%$ in the dates of regular review of the portfolio. This occurs every March (known in January) and the criteria to join the index are defined by the liquidity and market capitalization. The PSI-20 is an index of small caps, where only 5 companies have $61 \%$ of capitalization.

The S \& P (Standard \& Poors) 500 is an index composed of 500 stock representing $70 \%$ of all companies traded on U.S. exchange. It is considered a thermometer for the U.S. economy. The criteria for incorporation are qualified because of their market size, liquidity and its representation in the sector group. This method of selection opposes to the stiffness of PSI 20, since the list of companies that constitute the index GSPC is prepared by the Committee for S \& $\mathrm{P}$ indices, formed by several economists and analysts of reference. Standard \& Poor's is a financial consulting company and published for the first time the GSPC in March $4^{\text {th }} 1957$, with stock prices of large companies (Blue Chips) traded in the United States. The GSPC is the index followed by major U.S. companies. 
The Dow Jones EURO STOXX 50 is a leader in the euro area as a reference for the Blue Chips. The STOXX50 is a free-float market capitalization weighted index of 50 major companies from different sectors and countries of the Eurozone. It was developed on December $31^{\text {st }} 1991$ to provide a representation of the leading companies in the Eurozone. The country with major representation in the index is France (with $32 \%$ weight and 15 companies in the index). Portugal is not represented in this index. The weight of each component is limited to $10 \%$ of the capitalization of the index by free float market total.

The Russell 2000 index measures the performance of small cap segment of the universe of equity market in the United States. The RUT was developed on December $31^{\text {st }} 1986$ and is a reference for second-line operations in the United States, in order to provide a comprehensive and unbiased barometer of the market for small caps. The Russell 2000 is the most widely cited of the overall performance of small caps, while the S \& P 500 is mainly used for "blue chips". The Russell 2000 index is a subset of the Russell 3000 Index, representing approximately $8 \%$ of the total market capitalization of this index. The RUT includes the 2000 smallest companies in the Russell 3000 index, a broad-based index, which represents approximately 98\% of the market value of investment capital in the United States, but leaves out the mini-micro and small units that make up the remaining $2 \%$.

The Dow Jones STOXX 600 is derived from the Dow Jones STOXX Total Market Index and a subset of the Dow Jones STOXX Global 1800. With a fixed number of 600 companies, the STOXX includes large, medium and small size companies of 18 countries in Europe. Portugal has 10 companies in this index, with a total weight of $0.60 \%$. The STOXX Index is a broadbased capitalization-weighted European market and designed to provide a broad representation of companies in the European continent. The index was developed on December $31^{\text {st }} 1991$.

The Nikkei-225 (Nikkei 225 Heikin Kabuki) is the main index of the Stock Exchange in Tokyo (TSE) which is the second largest stock exchange in the world and is only behind the New York Stock Exchange. It presents the top 225 blue chip Japanese high-capitalization companies listed in the First Section of Tokyo Stock Exchange. The N225 was first published on May $16^{\text {th }} 1949$. Unlike other indices that have developed a system in real time, the Nikkei 225 is calculated by the traditional method and displayed daily by the business newspaper Nihon Keizai Shimbun. The N225 index is an index of weighted average price and its components are reviewed once a year.

The IBEX 35 (Iberia Index) is the benchmark stock market of the Madrid Stock Exchange, begun on 14 January 1992. It is an index weighted by market capitalization, according to the calculation of free float and is reviewed twice a year in which $51 \%$ of the weight of the index is in only 3 companies.

The data used in this study were daily taken from the rates above. The daily rate of return is defined as follows:

$$
n_{i}=\ln \frac{x_{i}}{x i-1}
$$


A sample of the series begins on January $4^{\text {th }} 1999$ and ends on December $31^{\text {st }}, 2008$. The citation index is made with reference to the Portuguese market, i.e., for values not available in their indexes in PSI20 is assigned the index value of the previous trading days, resulting in $\mathrm{N}=$ total 2 528 daily observations. Data were obtained from Bloomberg Finance.

With the presented series we intend to go through some of the most significant moments in the capital markets, in particular, when the Asian crisis of 1997 was devalued, and afterwards fell Malaysia, Indonesia and the Philippines, which also affected Taiwan, Hong Kong and South Korea. The effect dragged the rest of the economy and this crisis that at first appeared to be regional, eventually became the first global crisis, partly influenced by the Ruble crisis in 1998, when the national banking system in Russia collapsed with the partial suspension of international payments, causing the devaluation of the Ruble and the freezing of foreign currency deposits.

In 2000 came the crisis of DotCom (tech bubble). The excesses of the new economy left a trail of bankruptcies, purchases and mergers in the Internet and telecommunications and a large hole in the accounts of risk capital.

The attacks of September 11, 2001 against the Twin Towers in New York and the Pentagon in Washington caused the stock collapse, and consequently the closure of the New York Stock Exchange for a week, and in its reopening, the Dow Jones suffered the greatest loss of history. The forgery of the accounts of the American company Enron and the fraud of the telecommunications group Wordcom in 2002 destabilized the stock of the world, causing mistrust among investors in relation to reports made available by companies.

In 2008, as a result of the crisis caused by mortgage loans with high risk - Subprime, there was another collapse. The loans were granted at a variable rate to families so called "fragile", i.e., no income, no job and no assets. In fact, they were financing homes, often in conjunction with the issuance of credit to other family household; whom they knew didn't had sufficient income to assume those instalments. Then these banks created derivative products traded in financial markets on these mortgages, instruments to securitize, that is, turn them into freely tradable securities that were sold to other banks, financial institutions, insurance companies and pension funds around the world. Thus, creating the toxic assets. For a reason that is unknown, the global credit agencies gave AAA rating to these securities.

In 2005 the FED raised interest rates to try to reduce inflation, causing the fall in property prices, and making refinancing impossible for customers who had become non-compliant mass derived from these securities, becoming impossible to be traded at any price, which triggered a domino effect, swaying the international banking system, from August 2007 on. On September $15^{\text {th }} 2008$, this crisis caused the collapse on a colossal area of banking investment - Lehman Brothers - and a few days after the bankruptcy of the largest insurer AIG, caused the most serious crisis since the thirties. The crisis created thunderous losses around the world in the most important financial institutions, Citigroup and Merrill Lynch, in the United States; Northerb Rock, in the UK, Swiss Re and UBS in Switzerland, Societe Generale, France; Sadia, Aracruz and Votorantim in Brazil. In Figure 1 we can see the periods of crisis represented by higher and longer falls. 


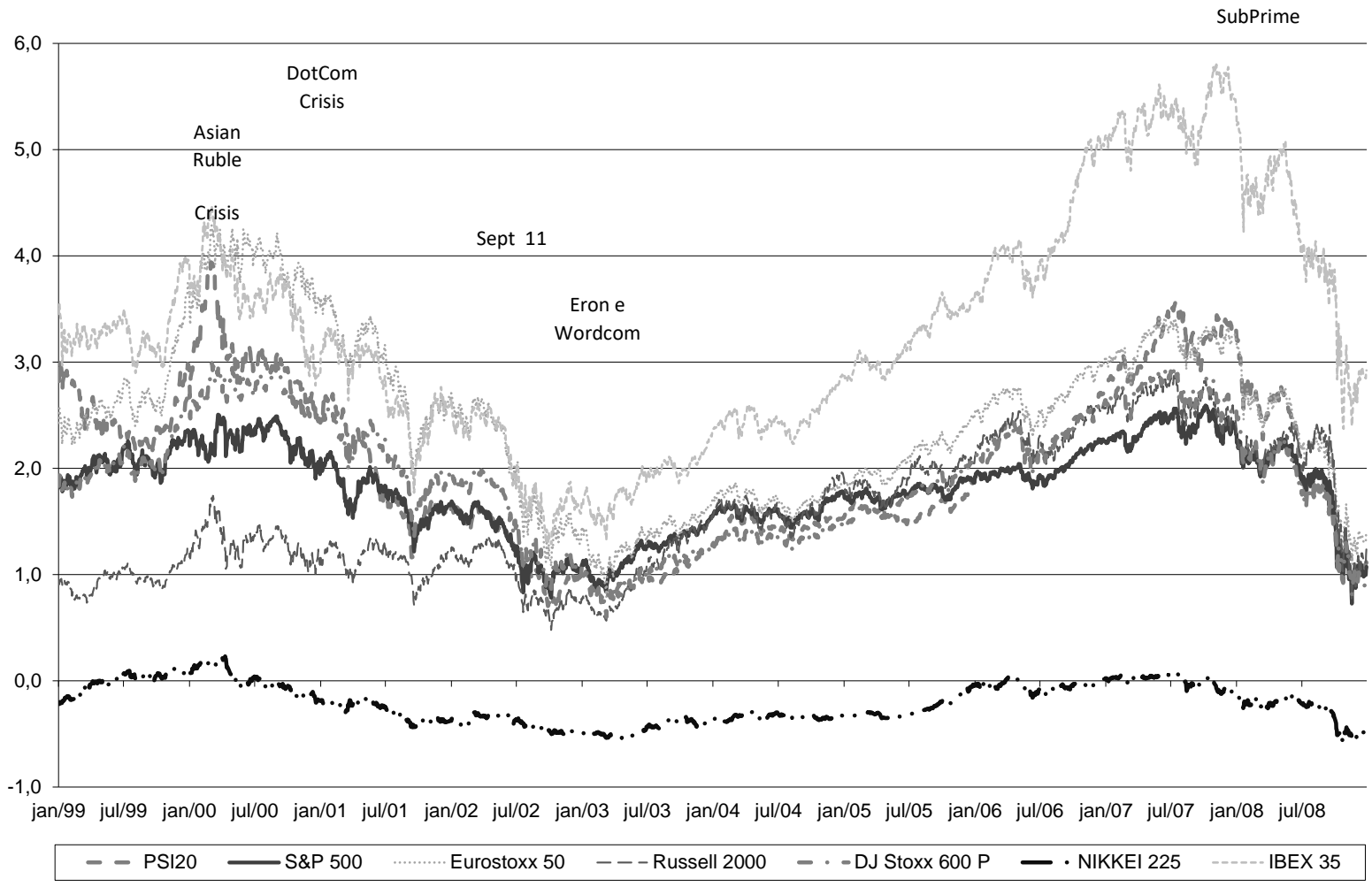

Figure 1: Daily change of indices

In the sample period it is characterized a null return of the daily average for all indices. The maximum variation occurs daily in all indexes on October $13^{\text {th }} 2008$, the minimum variation also occurs in October but in different days, as we may see in the table 3:

Table3: Daily variations of the indices during the sampling period with larger variations

\section{Daily Variations}

\begin{tabular}{lll|lll}
\hline \multirow{2}{*}{ Index } & \multicolumn{2}{c}{$\begin{array}{c}\text { Positive } \\
\text { Date }\end{array}$} & $\begin{array}{l}\text { Variation } \\
\text { Date }\end{array}$ & & Negative \\
& Dariation \\
\hline PSI20 & $13-10-08$ & $4.2 \%$ & $06-10-08$ & & $-4.5 \%$ \\
\hline SPX & $13-10-08$ & $4.8 \%$ & $15-10-08$ & $01-12-08$ & $-4.1 \%$ \\
\hline SX5E & $13-10-08$ & $4.5 \%$ & $06-10-08$ & $10-10-08$ & $-3.6 \%$ \\
\hline RTY & $13-10-08$ & $3.8 \%$ & $01-12-08$ & & $-5.5 \%$ \\
\hline SXXP & $13-10-08$ & $4.1 \%$ & $06-10-08$ & $10-10-08$ & $-3.4 \%$ \\
\hline NKY & $14-10-08$ & $5.7 \%$ & $16-10-08$ & & $-5.3 \%$ \\
\hline IBEX & $13-10-08$ & $4.4 \%$ & $10-10-08$ & & $-4.2 \%$ \\
\hline
\end{tabular}

These disparities in October can be explained due to so far unique factors in the world economy. The GDP of the Eurozone fell by $1.5 \%$ in the fourth quarter of 2008 compared to the previous quarter, the biggest contraction in economic history of the area. The IMF on October $7^{\text {th }}$ presented losses from the subprime around 1.4 trillion dollars and total value of subprime loans still at risk amounted to 12.3 trillion, representing $89 \%$ of GDP. The fall of the fifth-largest investment bank Bear Stearns, despite the measures implemented by the Federal Reserve, was inevitable. On October $11^{\text {th }}$ the Secretary of the Treasury of the United States met with 
representatives of major banks in the United States in order to present the actions of that government to end the crisis in the financial system. The state injected 700 billion dollars in the bank to buy the toxic products and in return became a shareholder of the banks.

On October $29^{\text {th }} 1929$ took place the crash of the New York Stock Exchange and on October $19^{\text {th }}$ 1987 due to widespread mistrust of investors, there was a massive sale of shares in the New York Stock Exchange causing declines in world stock markets. This phenomenon became known as the "Black Monday", is it typical of October? Or this is the "Black October"?

\section{Empirical Study}

Stock markets are typically volatile. However and contrary to the returns, volatility is not directly observable being necessary to proceed with the calculation by the annualized standard deviation of logarithmic returns. The volatility is presented, usually in an annualized way by multiplying the daily standard deviation by the square root of the number of observations considered normal frequency estimation: $\sqrt{280}$ for daily data. It is considered essential for determining the capital requirements of the various agents with known exposure to market risk. The presentation of volatility, together with the correlation is justified by the existence of relationship with the returns of the indices.

Table 4: Index Returns

\begin{tabular}{llllllll}
\hline $\begin{array}{l}\text { Returns } \\
\text { Year }\end{array}$ & PSI20 & GSPC & STOXX50E & RUT & STOXX & N225 & IBEX \\
\hline 1999 & $8.74 \%$ & $18.88 \%$ & $46.74 \%$ & $20.56 \%$ & $35.92 \%$ & $36.79 \%$ & $18.35 \%$ \\
\hline 2000 & $-13.01 \%$ & $-9.85 \%$ & $-2.69 \%$ & $-2.63 \%$ & $-5.19 \%$ & $-27.19 \%$ & $-21.75 \%$ \\
\hline 2001 & $-24.73 \%$ & $-12.06 \%$ & $-20.25 \%$ & $2.09 \%$ & $-16.97 \%$ & $-23.52 \%$ & $-7.82 \%$ \\
\hline 2002 & $-25.62 \%$ & $-24.22 \%$ & $-37.30 \%$ & $-22.39 \%$ & $-32.47 \%$ & $-18.63 \%$ & $-28.11 \%$ \\
\hline 2003 & $15.84 \%$ & $26.38 \%$ & $15.68 \%$ & $45.37 \%$ & $13.68 \%$ & $24.45 \%$ & $28.17 \%$ \\
\hline 2004 & $12.64 \%$ & $8.99 \%$ & $6.90 \%$ & $17.00 \%$ & $9.47 \%$ & $7.61 \%$ & $17.37 \%$ \\
\hline 2005 & $13.40 \%$ & $3.00 \%$ & $21.28 \%$ & $3.32 \%$ & $23.51 \%$ & $40.24 \%$ & $18.20 \%$ \\
\hline 2006 & $29.92 \%$ & $13.62 \%$ & $15.12 \%$ & $17.00 \%$ & $17.81 \%$ & $6.92 \%$ & $31.79 \%$ \\
\hline 2007 & $16.27 \%$ & $3.53 \%$ & $6.79 \%$ & $-2.75 \%$ & $-0.17 \%$ & $-11.13 \%$ & $7.32 \%$ \\
\hline 2008 & $-51.29 \%$ & $-38.49 \%$ & $-44.37 \%$ & $-34.80 \%$ & $-45.60 \%$ & $-42.12 \%$ & $-39.43 \%$ \\
\hline Total & $-17.84 \%$ & $-10.21 \%$ & $7.89 \%$ & $42.77 \%$ & $-0.02 \%$ & $-6.60 \%$ & $24.09 \%$ \\
\hline Average & $-1.78 \%$ & $-1.02 \%$ & $0.79 \%$ & $4.28 \%$ & $0.00 \%$ & $-0.66 \%$ & $2.41 \%$ \\
\hline
\end{tabular}

On the analysis to the previous table we can see that on average, the indexes with more titles managed to get higher return indices with fewer titles. The most interesting is that this gain in terms of profitability was not achieved at the expense of an increase in overall risk. 
Table 5: Index Volatility

\begin{tabular}{llllllll}
\hline & \multicolumn{7}{c}{ Risk (Standard - Deviation) } \\
Year & PSI20 & GSPC & STOXX50E & RUT & STOXX & N225 & IBEX \\
\hline 1999 & $7.92 \%$ & $8.30 \%$ & $9.27 \%$ & $6.58 \%$ & $7.64 \%$ & $9.32 \%$ & $9.42 \%$ \\
\hline 2000 & $9.95 \%$ & $10.17 \%$ & $10.66 \%$ & $13.62 \%$ & $8.73 \%$ & $10.48 \%$ & $11.30 \%$ \\
\hline 2001 & $8.56 \%$ & $9.94 \%$ & $12.68 \%$ & $10.79 \%$ & $10.58 \%$ & $13.43 \%$ & $12.48 \%$ \\
\hline 2002 & $8.26 \%$ & $12.04 \%$ & $17.18 \%$ & $11.71 \%$ & $13.05 \%$ & $11.80 \%$ & $14.03 \%$ \\
\hline 2003 & $5.42 \%$ & $7.75 \%$ & $12.33 \%$ & $8.63 \%$ & $9.63 \%$ & $10.28 \%$ & $9.23 \%$ \\
\hline 2004 & $4.76 \%$ & $4.98 \%$ & $6.38 \%$ & $8.09 \%$ & $5.20 \%$ & $7.98 \%$ & $5.93 \%$ \\
\hline 2005 & $3.79 \%$ & $4.65 \%$ & $5.01 \%$ & $7.32 \%$ & $4.26 \%$ & $6.01 \%$ & $4.61 \%$ \\
\hline 2006 & $4.21 \%$ & $4.53 \%$ & $6.68 \%$ & $7.88 \%$ & $5.82 \%$ & $8.95 \%$ & $6.14 \%$ \\
\hline 2007 & $6.39 \%$ & $7.29 \%$ & $7.25 \%$ & $9.28 \%$ & $7.32 \%$ & $8.29 \%$ & $7.44 \%$ \\
\hline 2008 & $15.00 \%$ & $18.64 \%$ & $17.88 \%$ & $21.14 \%$ & $16.66 \%$ & $20.83 \%$ & $18.11 \%$
\end{tabular}

In order to compare the volatilities of the sample we calculated the annual volatility of the indices referenced in this study, represented in Figure 2. We can see that in 2008 all the indices peaked and volatility more than doubled the 2007. 2005 has the lowest volatility.

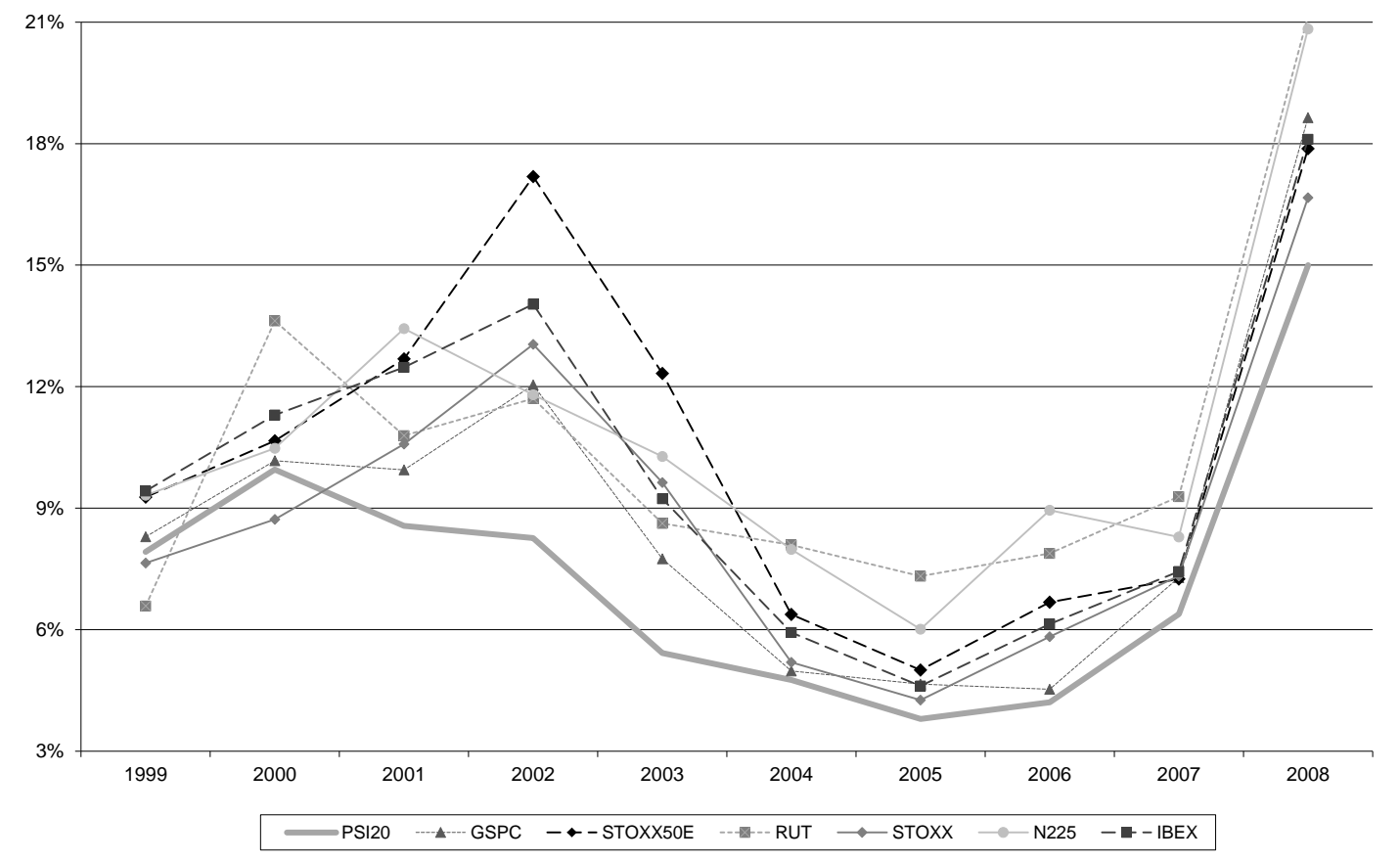

Figure 2: Annual volatility indices

From 2001 on is visible a major distance from the volatility of the PSI-20 in relation to other indexes. However, from 2005 on there is a clear convergence in the volatility in all indices where the PSI20 always displays the lowest volatility. The volatility of an index can be easily calculated by calculating the standard deviation (or variance) of daily returns of the index. This is a direct and quicker way to calculate the volatility of a share index. The return of an index represents the weighted average of returns of assets that comprise the index:

$$
r I_{t}=\sum_{i=1}^{n} x_{i} \times r_{i}
$$


As $r I$ profitability index, $x i$ the weight of asset $i$ in the index and $r I$ the return on asset $i$. On the other hand the variance of an index is represented by:

$\operatorname{Var}\left[r I_{t}\right]=\sum_{i=1}^{n} x_{i}^{2} \times \sigma_{i}^{2}+2 \times \sum_{i=1}^{n} \sum_{j=1, j \neq 1}^{n} \rho_{i j} \sigma_{i} \sigma_{j} x_{i} x_{j}$

If we assume that the variance of different assets that constitute the index equals $\left(\sigma_{i}^{2}=\sigma^{2}\right)$, and the correlation coefficient between assets is also similar $\left(\rho_{i j}=\rho\right)$ then the expression above is:

$\operatorname{Var}\left[r I_{t}\right]=\sum_{i=1}^{n} x_{i}^{2} \times \sigma^{2}+2 \times \rho \sigma^{2} \sum_{i=1}^{n} \sum_{j=1, j \neq 1}^{n} x_{i} x_{j}$

Accurate estimates and correct predictions on the volatility of assets and the correlation is mandatory in most financial applications in order to provide a more comprehensive information to investors who are in face of uncertain markets.

Miscellaneous information about the correlation of the markets indicates that this is higher during the Bear Market, as an example we have the reference from an article published in February 2002 in the Financial Analysts Journal, Campbell, Koedijk and Kofman. In this chapter we find that for the Portuguese market this rule remains.

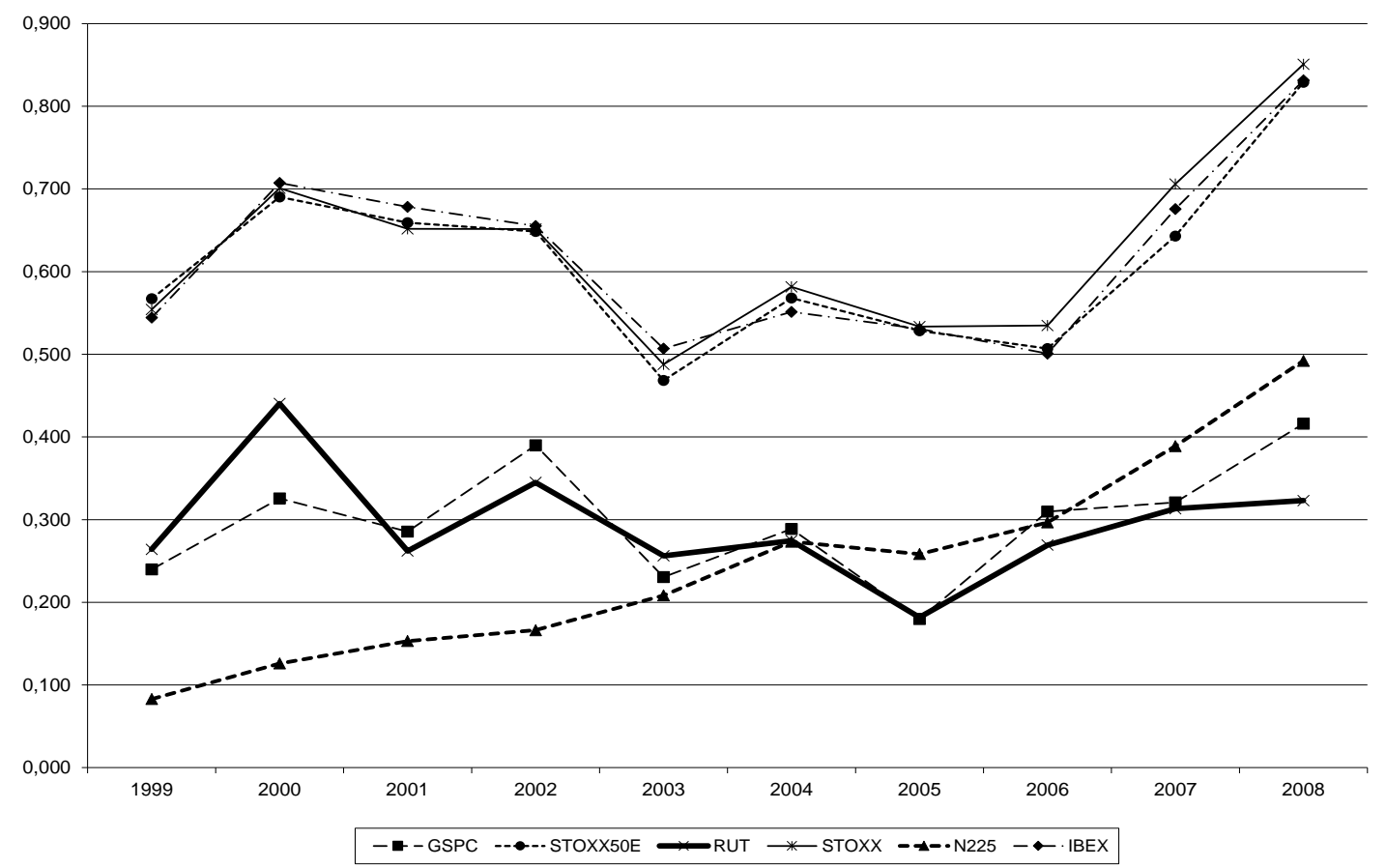

Figure 3: Correlation with other indices PSI20

The PSI20 has a strong correlation with the indexes assigned in the European market and moderate with the other indexes present in this study. In Figure 3 we can see the strong relationship that volatility has on the correlation of the indices, however, it is not the only explanation. 
The correlation of the indices in the 10 years proposed for this study is always positive, fluctuating between 0.117 (S \& P 500 / Nikkei 225) and 0.965 (Eurostoxx 50 / DJ Stoxx 600). The overall average correlation is 0.503 . The Nikkei 225 has the lowest correlation with other indices, with an average of 0.233 . These lower correlations are partly explained by the nonoverlapping trading hours of the Asian markets with the European and North American. Eurostoxx 50 and DJ Stoxx 600 have the highest average correlations of 0.634 and 0.638 , accordingly. The PSI 20 has the highest correlation with the IBEX 0687.

Table 6: Correlation of Indexes

\begin{tabular}{lcllllll}
\hline & PSI20 & GSPC & STOXX50E & RUT & STOXX & N225 & IBEX \\
\hline PSI20 & 1 & & & & & \\
\hline GSPC & 0.343 & 1 & & & & & \\
\hline STOXX50E & 0.658 & 0.527 & 1 & & & & \\
\hline RUT & 0.315 & 0.870 & 0.471 & 1 & & & \\
\hline STOXX & 0.686 & 0.529 & 0.965 & 0.475 & 1 & \\
\hline N225 & 0.294 & 0.117 & 0.287 & 0.099 & 0.326 & 1 & \\
\hline IBEX & 0.687 & 0.469 & 0.895 & 0.430 & 0.846 & 0.276 & 1 \\
\hline Average & 0.497 & 0.476 & 0.634 & 0.443 & 0.638 & 0.233 & 0.601 \\
\hline$N$ & 2527 & 2527 & 2527 & 2527 & 2527 & 2527 & 2527 \\
\hline Volatility & $7.43 \%$ & $8.83 \%$ & $10.53 \%$ & $10.51 \%$ & $8.89 \%$ & $10.74 \%$ & $9.87 \%$ \\
\hline
\end{tabular}

To go further into the nature of correlations, we divided the sample into periods of Bull and Bear Market in accordance with the slope of the trend index of the world market, and we verified that Bull and Bear Markets are consolidated when the index line overcomes the Moving Average of 150 days.

Table 7: Identification of periods Bull and Bear Market sample

\begin{tabular}{lllll}
\hline & Bull & Bear & Bull & Bear \\
\hline PSI20 & $03-03-2000$ & $23-10-2002$ & $17-07-2007$ & $31-12-2008$ \\
\hline GSPC & $24-03-2000$ & $09-10-2002$ & $10-09-2007$ & $31-12-2008$ \\
\hline STOXX50E & $06-03-2000$ & $12-03-2003$ & $16-07-2007$ & $31-12-2008$ \\
\hline RUT & $09-03-2000$ & $09-10-2002$ & $13-07-2007$ & $31-12-2008$ \\
\hline STOXX & $06-03-2000$ & $12-03-2003$ & $01-06-2007$ & $31-12-2008$ \\
\hline N225 & $14-04-2000$ & $28-04-2003$ & $09-07-2007$ & $31-12-2008$ \\
\hline IBEX & $06-03-2000$ & $09-10-2002$ & $08-11-2007$ & $31-12-2008$ \\
\hline
\end{tabular}

We must first define the regimes where rates are falling or rising. Then assess whether the markets during these periods are equal than the average of the sampling period. Periods of Bull and Bear Market are different, thus the table we present for the study of markets is different for the total sample. The first period of Bull Market is the result of recovery of the Asian crisis known as "the first great crisis of globalized markets" and the Russian financial crisis. The average correlation in this period is 0.414 . The index that had a higher rise time was the N225. However, it is also the one that had less correlation with other indices. There is a strong correlation between the indices STOXX50 and STOXX, but the index PSI20 presents major correspondence on these. 
Table 8: Correlations between the indices in the 1st period Market Bull

\begin{tabular}{llllllll}
\hline & \multirow{2}{*}{ PSI20 } & \multirow{2}{*}{ GSPC } & $\begin{array}{l}\text { STOXX50 } \\
\mathrm{E}\end{array}$ & \multirow{2}{*}{ RUT } & \multirow{2}{*}{ STOXX } & \multirow{2}{*}{ N225 } & \multirow{2}{*}{ IBEX } \\
\hline PSI20 & 1 & 0.173 & 0.583 & 0.301 & 0.581 & 0.105 & 0.580 \\
\hline GSPC & 0.234 & 1 & 0.408 & 0.710 & 0.411 & 0.034 & 0.341 \\
\hline STOXX50E & 0.583 & 0.376 & 1 & 0.470 & 0.936 & 0.234 & 0.814 \\
\hline RUT & 0.305 & 0.668 & 0.471 & 1 & 0.469 & 0.012 & 0.393 \\
\hline STOXX & 0.582 & 0.383 & 0.936 & 0.471 & 1 & 0.247 & 0.801 \\
\hline N225 & 0.104 & 0.029 & 0.225 & 0.034 & 0.242 & 1 & 0.140 \\
\hline IBEX & 0.580 & 0.296 & 0.814 & 0.389 & 0.801 & 0.137 & 1 \\
\hline Average & 0.398 & 0.321 & 0.573 & 0.396 & 0.574 & 0.128 & 0.511 \\
\hline$N$ & 294 & 308 & 295 & 297 & 295 & 323 & 295 \\
\hline
\end{tabular}

The first Bear Market referred in this study includes the DotCom crisis, the economic crisis in Argentina, September $11^{\text {th }}$ and the case of Eron and Wordcom. We found an exponential increase in the correlation of the GSPC and RUT indexes with the N225, although this remains rather weak. The correlation of PSI20 increased significantly, being the highest correlation now with the neighbouring market, IBEX35. However, the biggest increase was the S \& P 500, which increased $45 \%$, due to the epicentre of this crisis being in the United States. The average correlation increased $14 \%$, leaving in 0.474 .

Table 9: Correlations between the indices in the 1st period Market Bear

\begin{tabular}{llllllll}
\hline & PSI20 & GSPC & STOXX50E & RUT & STOXX & N225 & IBEX \\
\hline PSI20 & 1 & 0.363 & 0.629 & 0.355 & 0.636 & 0.155 & 0.673 \\
\hline GSPC & 0.340 & 1 & 0.526 & 0.837 & 0.518 & 0.135 & 0.411 \\
\hline STOXX50E & 0.648 & 0.504 & 1 & 0.462 & 0.968 & 0.168 & 0.873 \\
\hline RUT & 0.354 & 0.851 & 0.486 & 1 & 0.485 & 0.145 & 0.398 \\
\hline STOXX & 0.654 & 0.507 & 0.968 & 0.472 & 1 & 0.196 & 0.848 \\
\hline N225 & 0.141 & 0.133 & 0.179 & 0.126 & 0.205 & 1 & 0.160 \\
\hline IBEX & 0.676 & 0.427 & 0.878 & 0.398 & 0.856 & 0.162 & 1 \\
\hline Average & 0.469 & 0.464 & 0.611 & 0.441 & 0.611 & 0.160 & 0.560 \\
\hline$N$ & 649 & 625 & 743 & 636 & 743 & 746 & 638 \\
\hline
\end{tabular}

The second period of Bull Market is the longest in this study. In the United States were implemented various measures to protect investors, such as low policy interest rates and the implementation of various financial innovations so complex that government financial authorities have become technically unable to assess the risks of these instruments. The correlation is moderate in this period, having increased by only $2 \%$. We stress the very strong correlation, existing in the former Bear, among STOXX50 and STOXX indexes, and strong correlation with the IBEX. The PSI20 presents a breakdown of $17 \%$, maintaining the highest correlation with the IBEX. 
Table 10: Correlations between rates in the 2nd period Market Bull

\begin{tabular}{llllllll}
\hline & PSI20 & GSPC & STOXX50E & RUT & STOXX & N225 & IBEX \\
\hline PSI20 & 1 & 0.273 & 0.492 & 0.253 & 0.512 & 0.270 & 0.566 \\
\hline GSPC & 0.253 & 1 & 0.525 & 0.872 & 0.506 & 0.109 & 0.517 \\
\hline STOXX50E & 0.511 & 0.576 & 1 & 0.503 & 0.965 & 0.314 & 0.907 \\
\hline RUT & 0.246 & 0.874 & 0.477 & 1 & 0.462 & 0.165 & 0.475 \\
\hline STOXX & 0.529 & 0.543 & 0.966 & 0.481 & 1 & 0.339 & 0.899 \\
\hline N225 & 0.250 & 0.101 & 0.270 & 0.167 & 0.303 & 1 & 0.255 \\
\hline IBEX & 0.532 & 0.520 & 0.908 & 0.481 & 0.895 & 0.300 & 1 \\
\hline Average & 0.387 & 0.481 & 0.606 & 0.460 & 0.607 & 0.250 & 0.603 \\
\hline$N$ & 1208 & 1257 & 1112 & 1216 & 1081 & 1076 & 1300 \\
\hline
\end{tabular}

In the latter period of Bear Market, our study focuses on Subprime crisis (the worst crisis since the crash of 1929) which is strongly related to measures designed to restore the crisis in 2000. In this period there is a clear increase in the average correlation across all indices, except in the RUT suffering a slight drop of 4\%. The PSI20 has a strong correlation with the European indices, however, STOXX is the one which has a higher correlation. GSPC index is highly correlated with the RUT. The N225 is still the index that has less correlation, despite the increase of $14 \%$. It was in this period that there was the greatest increase in average correlation of $14 \%$.

Table 11: Correlations between rates in the 2nd period Market Bear

\begin{tabular}{llllllll}
\hline & PSI20 & GSPC & STOXX50E & RUT & STOXX & N225 & IBEX \\
\hline PSI20 & 1 & 0.407 & 0.812 & 0.318 & 0.835 & 0.477 & 0.823 \\
\hline GSPC & 0.405 & 1 & 0.569 & 0.931 & 0.571 & 0.117 & 0.528 \\
\hline STOXX50E & 0.812 & 0.570 & 1 & 0.460 & 0.979 & 0.432 & 0.943 \\
\hline RUT & 0.319 & 0.932 & 0.460 & 1 & 0.471 & 0.036 & 0.440 \\
\hline STOXX & 0.836 & 0.576 & 0.979 & 0.471 & 1 & 0.465 & 0.936 \\
\hline N225 & 0.476 & 0.128 & 0.432 & 0.037 & 0.464 & 1 & 0.437 \\
\hline IBEX & 0.820 & 0.527 & 0.942 & 0.439 & 0.934 & 0.422 & 1 \\
\hline Average & 0.611 & 0.523 & 0.699 & 0.443 & 0.709 & 0.325 & 0.685 \\
\hline$N$ & 373 & 334 & 374 & 375 & 405 & 379 & 291 \\
\hline
\end{tabular}

We can see how the PSI20 has a regional behaviour, i.e., a strong correlation with the close markets. Since the effects of contagion occur among neighbouring markets, the same applies to foreign investment in the Japanese stock market, concentrated mainly in the large national companies, which have a greater international visibility. The entry in February 2002 of currency EURO also increases the correlation, through the high risk aversion rate, or even through evidence of asymmetric information, for instance in relation to the expectations of the price of the currency. The overlap of working hours is instrumental in the correlation, especially in the N225, because the most common trading hours increased the level of correlation of share price. For an advocate of the hypothesis of market efficiency, in which asset prices correctly anticipates the info from the movement in the market, indicate that the markets are reacting to the "simultaneously global news" and changes in prices lead to increased correlation. King and Wadhwani (1990) provide evidence of contagion between the markets of London and New York, where the results of synchronous trading does not occur due to an attempt by investors to infer 
information from price changes in another market. The common operating hours, can facilitate the dissemination of information among investors, reducing the asymmetries mentioned.

Opening times/overlap remains an important explanatory variable. This leads us to believe that differences in investor information, rather than to facilitate the negotiation can be noisy for the same. We found that in the four presented periods the correlation increased, with greater focus on periods of Bear Market. The justification for this continuous increase in the correlation between the markets has been attributed to globalization and the integration of financial markets and therefore reverts to reduce the benefits of diversification. It is also thought that the correlation of extreme movements in asset prices of financial markets can significantly exceed the overall correlation between the returns of assets. The models for the selection of the investment portfolio and its success in real world applications depend crucially on the correlation of the assets market. In terms of risk reduction, the correlation coefficient is the most important in any model of asset allocation. The study of the correlation is an important issue in financial econometrics, which has received great attention in the finance literature. Initially the correlation was regarded as one variable constant and unconditional, but studies have provided empirical evidence that allowed the recognition of the connection as dynamic: for example, Von Füstenberg and Jeon, 1989.

We intend, therefore, with the analysis of the period 1999 to 2008 and the division of this period into Bull and Bear Market, to actually corroborate the idea that large movements in equity markets are more correlated during low periods and that there is some difference in behaviour between the Bull and Bear Markets.

\section{Conclusions}

One first remark is about the importance that the correlation factors have in fact, in the optimization of portfolios' investment. The second concerns the fact that the overlap of opening hours can capture many effects, namely the markets' reaction to the world news, through the contagion of market, the easiness on negotiations with other participants in other location. In particular, the major market indexes tend to be correlated, since they react more quickly and have a greater range of information. This result is consistent with empirical studies of Ang and Chen (2002) indicating that the observed increase in dependency of the phenomenon during the Bear Market is resultant from a regime of greater volatility, but not entirely.

Thus, this study focused on the dependence of the correlation of the stock market returns in different countries and with volatility also quite different. Starting with the definition of correlation, our main contribution was to propose an analysis of the correlation PSI20 and 6 other indices for the period 1999 to 2008, and the division of Bear and Bull Market into these periods selected for the study. The basic idea was, therefore, select some indexes that we think have the greatest impact on the analysis of investments in capital markets. The markets in our study were: North America (S \& P500 [Blue Chips] and Russell 2000 [Small Caps]), Asia Japan (Nikkei225) and Europe (DJ Stoxx 600), the Eurozone (Eurostoxx 50), Spain (IBEX 35). Considering the small size of the Portuguese stock market, this study provided an opportunity to investigate whether the correlations among the small markets behave differently from those that occur in major markets. The empirical analysis of the stock market returns was made with the 
daily data in the period 1999-2008. Samples confirmed that the correlation is stronger when the index of world market is trending downward. We found that large increases in volatility can substantially change the correlations. These results corroborate previous studies that found correlations with each other, as considered by many experts (Solnik, Boucrelle and Fur (1996), Ramchand and Susmel (1998), Dennis, Mayhew and Stivers (2005), Baele (2005), and others). We also think that the correlations between the stock market returns have been increasing throughout the world during the Bear Market (Longin and Solnik (1995), Ang and Chen (2002), and others), but this relationship is presented in a smaller magnitude than volatility. Other results showed that most of the correlations between the indices have increased from 1999 to 2008. An example of this increase in correlation was Subprime crisis of 2008. Thus, the increase in market correlations reported by Longin and Solnik (1995) for the period 1960 to 1990 has continued in recent years.

This trend is probably due to the increase in global capital flows and financial market integration coincidental. Finally, it was found that the results of a simultaneous correlation, using daily returns for the European countries with trading hours/overlay to be more reliable than the ones of the world market, with trading hours that do not overlap. Using the Pearson coefficient we estimated correlations for each of the equity markets, as well as in Bear and Bull Markets. The results show that the correlation of markets has been increasing in recent years. However, this greater degree of correlation is not observed for the N225 here considered that in addition appears to be correlated with the markets of the Eurozone rather than with the United States. In times of financial crisis, we easily get the impression of contagion and its impact on all financial markets. This suggests that the returns of financial assets are highly correlated for large negative returns. If this intuition is supported with repeatedly empirical evidence, we will have serious implications for the allocation of the portfolio based on the premise of diversification.

It appears that the benefits of diversification depend critically on assets that have low or negative correlation. These benefits would be severely affected by an increasing correlation. In fact, when these benefits of diversification are most need, quickly disappear. For investors worried about downside risk, this would imply a reformulation of the model of the average change in portfolio allocation. One of the advantages of diversification is that when one asset category is in decline the other is raising, that is, the theory is that diversification reduces risk and volatility of the portfolio. Harry Markowitz, Nobel Prize winner in 1990 and pioneer of the "Modern Portfolio Theory," devised a way to maximize return for a given level of risk: the basis is that diversification across many asset's categories should maximize the return for a given level of risk if the portfolio is invested according to the Markowitz Efficient Frontier. But if all asset's categories move in unison, then this investment technique cannot provide protection against the risk heralded by the theory. The correlation seems to be increasing and investments may be linked more than ever, there are no mechanisms to protect their bets and thrive in highly correlated. With the increase of the correlations between the markets we cannot withdraw the benefit of diversification: Harry Markowitz showed that an investor can reduce risk in the portfolio simply if it has non-correlated assets, arguing that diversification leads to reducing the risk of a portfolio, but not necessarily reduce the profitability.

Recently, with markets increasingly moving in sync, it seems that the increase in correlation could disrupt this fundamental rule of portfolio theory. Based on the study of market behaviour 
over the past 10 years, and based on daily returns of major indices, we analyse how the correlations behave over time. There is an increased access of investors to asset categories, traditionally restricted to institutional investors and individuals of highly net valued. Investors must accept that the correlations do not establish immutable regularities. The development described here does not undermine the underlying principles of Markowitz with the modern theory of portfolio investment. Still, there is no reason to panic, because the benefit of diversification continues - although at a lower level. Indeed, there are opportunities even in times of turbulence. However, throughout the world the portfolio diversification remains essential. In order to continue to capitalize on the effect of reducing risk, investors should learn to adjust to market standards and make a proper analysis of the correlations in the construction of the portfolio. The contribution of the work proposed here is to analyse the correlation and we have found that it increases significantly during the crisis, indicating contagious effects in all markets.

\section{References}

[1] Andrew Ang, Joseph Chen, and Yuhang Xing. (2002). "DOWNSIDE CORRELATION AND EXPECTED STOCK RETURNS.” Working Paper, Columbia Business School.

[2] John Ammer, and Jianping Mei. (1996). "MEASURING INTERNATIONAL ECONOMIC LINKAGES WITH STOCK MARKET DATA.” Journal of Finance, 51, 1743-1763.

[3] Lieven Baele. (2005). "VOLATILITY SPILLOVER EFFECTS IN EUROPEAN EQUITY MARKETS." Journal of Financial and Quantitative Analysis, 40, 373-401.

[4] Vincent Bodart, and Paul Reding. (1999). "EXCHANGE RATE REGIME, VOLATILITY AND INTERNATIONAL CORRELATIONS ON BOND AND STOCK MARKETS.” Journal of International Money and Finance, 18, 133-151.

[5] Kirt Charles Butler, and Domingo Castelo Joaquin. (2002). "ARE THE GAINS FROM INTERNATIONAL PORTFOLIO DIVERSIFICATION EXAGGERATED? THE INFLUENCE OF DOWNSIDE RISK IN BEAR MARKETS.” Journal of International Money and Finance, 21(7), 981-1011.

[6] Rachel Campbell, Kees Koedijk, and Paul Kofman. (2002). "INCREASED CORRELATION IN BEAR MARKETS.” Financial Analyst Journal, 58, 87-94.

[7] Jacob Cohen, and Patricia Cohen. (1983). "APPLIED MULTIPLE REGRESSION CORRELATION ANALYSIS FOR THE BEHAVIOURAL SCIENCE.” Hillsdale NJ: Erlbaum

[8] Patrick Dennis, Stewart Mayhew, and Chris Stivers. (2005). "STOCK RETURNS, IMPLIED VOLATILITY INNOVATIONS, AND THE ASYMMETRIC VOLATILITY PHENOMENON." Journal of Financial and Quantitative Analysis.

[9] Sebastian Edwards. (1998). "INTEREST RATE VOLATILITY, CAPITAL CONTROLS, AND CONTAGION." NBER Working Paper 6756, National Bureau of Economic Research, Cambridge MA.

[10] Kristin J. Forbes, and Roberto Rigobon. (2002). "NO CONTAGION, ONLY INTERDEPENDENCE: MEASURING STOCK MARKET COMOVEMENTS." Journal of Finance, 57, 2223-2261.

[11] Eugene Francis Fama, and Kenneth Ronald French. (2000). "COMMON RISK FACTORS IN THE RETURNS ON STOCKS AND BONDS.” Journal of Financial Economics, 33, 3-56.

[12] Thomas James Flavin, Margaret Hurley, and Fabrice Rousseau. (2000). "EXPLAINING STOCK MARKET CORRELATION: A GRAVITY MODEL APPROACH.” NBER working paper, 7864.

[13] Patrick John Fitzgerald Groenen, and Philip Hans Franses. (2000). "VISUALIZING TIMEVARYING CORRELATIONS ACROSS STOCK MARKETS.” Journal of Empirical Finance, 7, 155-172. 
[14] Yasushi Hamao, Ronald Masulis, and Victor Ng. (1990). "CORRELATIONS IN PRICE CHANGES AND VOLATILITY ACROSS INTERNATIONAL STOCK MARKETS.” Review of Financial Studies, 281-307.

[15] Richard Heaney, Vincent Hooper, and Martin Jaugietis. (2000). "REGIONAL INTEGRATION OF NATIONAL STOCK MARKETS.” Asian Review of Accounting, 8, 55-65.

[16] Andrew Karolyi, and René Stulz. (1996). "WHY DO MARKETS MOVE TOGETHER? AN INVESTIGATION OF THE U.S.-JAPAN STOCK RETURN COMOVEMENTS.” Journal of Finance, 51, 951-986.

[17] Akysha Khan, and Shakil Ahmed (2009). "THE CORRELATION BETWEEN THE TRADING VOLUME AND STOCK RETURN IN KSE 100 INDEXES FLUCTUATE DUE TO EVENTS ARISE IN PAKISTAN." Working paper.

[18] Mervyn Allister King, and Sushil Wadhwani. (1990). "TRANSMISSION OF VOLATILITY BETWEEN STOCK MARKETS." Review of Financial Studies, 3, 5-33.

[19] Mervyn King, Enrique Sentana, and Sushil Wadhwani. (1994). "VOLATILITY AND LINKS BETWEEN NATIONAL STOCK MARKETS.” Econometrica, 62, 901-933.

[20] Johan Knif, James Kolari, and Seppo Pynnönen. (2005). "WHAT DRIVES CORRELATION BETWEEN STOCK MARKET RETURNS? INTERNATIONAL EVIDENCE.” NBER working paper 8109.

[21] Lee Gillam, Khurshid Ahmad, Saif Ahmad, Matthew Casey, David Cheng, Tugba Taskaya, Paulo de Oliveira, and Pensiri Manomaisupat. (2002). "ECONOMIC NEWS AND STOCK MARKET CORRELATION: A STUDY OF THE UK MARKET IN (ED.) LEE GILLAM, TERMINOLOGY AND KNOWLEDGE ENGINEERING." Making money in the financial services industry Proceedings of a workshop at the TKE 2002 conference.

[22] Sang Bin Lee, and Kwang Jung Kim. (1993). "DOES THE OCTOBER 1987 CRASH STRENGTHEN THE COMOVEMENTS AMONG NATIONAL STOCK MARKETS?” Review of Financial Economics, 3, 89-102.

[23] François Longin, and Bruno Solnik. (1995). "IS THE CORRELATION IN INTERNATIONAL EQUITY RETURNS CONSTANT: 1960-1990?” Journal of International Money and Finance, 14, 3-26.

[24] Latha Ramchand, and Raul Susmel. (1998). "VOLATILITY AND CROSS CORRELATION ACROSS MAJOR STOCK MARKETS.” Journal of Empirical Finance, 5, 397-416.

[25] Carmen Reinhart, and Sara Calvo. (1996). "Capital Flows to Latin America: Is There Evidence of Contagion Effects?" MPRA Paper 7124, University Library of Munich, Germany.

[26] Robert Stephen Pindyck, and Julio Jacobo Rotemberg. (1990). "DO STOCK PRICES MOVE TOGETHER TOO MUCH?” NBER Working Papers 3324, National Bureau of Economic Research, Inc.

[27] Rui Serra. (2002). "A VOLATILIDADE DOS ÍNDICES ACCIONISTAS PORTUGUESES E ÍNDICES ACCIONISTAS INTERNACIONAIS - A IMPORTÂNCIA DA CORRELAÇÃO.” Working paper.

[28] Bruno Solnik, Cyril Boucrelle, and Yann Le Fur. (1996). "INTERNATIONAL MARKET CORRELATION AND VOLATILITY." Financial Analysts Journal, 52, 17-34.

[29] George Von Furstenberg, and Bang Nam Jeon. (1989). "INTERNATIONAL STOCK PRICES MOVEMENTS: LINKS AND MESSAGES.” Brookings Papers on Economic Activity, 1, 125179.

[30] Williams (1968). “DESIGNED EXPERIMENTS.” Rubber Age, 100, 65-71.

*Corresponding author.

E-mail address: gualter.mm.couto@ uac.pt 